\title{
Impact of motorcycles on urban tropospheric ozone
}

\author{
L. F. A. Garcia ${ }^{1,2}$, S. M. Corrêa ${ }^{1}$, R. Penteado ${ }^{3}$, L. C. Daemme ${ }^{3}$, \\ L. V. Gatti ${ }^{4} \&$ D. S. Alvim ${ }^{4}$ \\ ${ }^{1}$ Universidade do Estado do Rio de Janeiro, Brazil \\ ${ }^{2}$ Instituto Estadual do Meio Ambiente, Brazil \\ ${ }^{3}$ Instituto de Tecnologia para o Desenvolvimento, Brazil \\ ${ }^{4}$ Instituto de Pesquisas Energéticas e Nucleares, Brazil
}

\begin{abstract}
The increased number of motorcycles in the large Brazilian cities is due to several factors such as traffic, low cost, mobility, few parking lots and low efficiency of public transportation, making it an important factor in air quality deterioration. In this context, vehicle emissions monitoring is essential to understanding the contribution on air pollution. Emissions of two representative motorcycles using gasohol (gasoline with $22 \%$ of ethanol) were evaluated on a dynamometer test bench and analyzed by gas chromatography mass spectrometry and on-line analyzers according to the EC/97/24 standard. Emission data obtained in combination with meteorological data and ambient air pollutants for the city of Rio de Janeiro (Brazil) during the winter of 2011, using the trajectory model OZIPR and chemical model SAPRC to assess the impact on the ozone forming potential in the troposphere of Rio de Janeiro city for the next years. The results indicate that ozone levels will exceed the established limits by national legislation within three years. The increase in ozone concentration occurs due to high emissions of reactive volatile organic compounds in an atmosphere with high levels of nitrogen oxides. Given this scenario, additional measures are necessary for the management of emissions from mobile sources.
\end{abstract}

Keywords: atmosphere, modelling, motorcycle, ozone, troposphere, VOC.

\section{Introduction}

Products of internal combustion engine vehicles can be considered one of the most polluting activities, mainly due to the large number of vehicles in cities. 
The low quality and quantity of public transportation is one of several reasons for vehicle fleet growth in metropolitan regions. According to the latest report on air quality for the state of São Paulo (Brazil), vehicles are responsible for $97 \%$ of $\mathrm{CO}, 77 \%$ of $\mathrm{HC}$ emissions, $82 \%$ of $\mathrm{NOx}, 36 \%$ of $\mathrm{SO}_{2}$ and $40 \%$ of $\mathrm{PM}$. In addition, motorcycles contribute $16 \%$ of the total $\mathrm{CO}$ and $13 \%$ of the total $\mathrm{HC}$ [1]. The high emission factors for such vehicles is due to the absence of electronic fuel injection, catalysts and anti-evaporation systems

Motorcycles are a rising form of transportation in large cities across the world, especially in emerging countries such as China, India and Brazil. The intensive use of motorcycles is explained by their high mobility in increasingly congested cities that lack affordable public transport, as a motorcycle with a less powerful engine $(150 \mathrm{cc})$ usually costs 20 to $25 \%$ that of a small car and is also associated with low fuel consumption, ease of parking and low maintenance cost. These advantages outweigh the inherent dangers of this form of transportation and other disadvantages such as interfering rain and the high cost of insurance. Brazil recorded 428,970 traffic accidents in 2008; the number of vehicles involved was 597,786, of which 246,712 were cars and 200,449 were motorcycles [2].

Given the facts presented and the potential increase in the amount of hydrocarbons in the atmosphere due to motorcycles, the net effect of ozone formation in cities such as Rio de Janeiro is also enhanced by high NOx levels. To perform simulations of tropospheric ozone formation from motorcycle emissions, the trajectory model OZIPR (Ozone Isopleth Package for Research) coupled with the chemical model SAPRC (State-wide Air Pollution Research Centre) was used [3].

This study aimed to assess the overall impact of motorcycle emissions on air quality in large cities such as Rio de Janeiro by studying the profile of current fleets and estimates for future scenarios and identifying their issues in classes of compounds.

\section{Experimental}

\subsection{Motorcycle emissions sampling}

Samples were collected during emissions testing in a dynamometer bench (AVL Zöllner model AN $40770,648 \mathrm{~mm}, 100 \mathrm{~kW})$. Two motorcycles were tested $\left(150 \mathrm{~cm}^{3}\right.$, and $125 \mathrm{~cm}^{3}$ engine displacement, respectively named BK01 and BK02, respectively). Both were Euro III models with EFI, catalyst, and 2009 model. The exhaust emissions were measured using commercial gasoline with $22 \% \mathrm{v} / \mathrm{v}$ of ethanol.

Tests were conducted over a chassis dynamometer according to the 97/24/EC drive cycle, which is divided into six primary modules and one extra-urban cycle. Regulated emissions (CO, HC and NOx) have been measured with 7000 series Horiba benches. Each cycle includes four modes (idling speed, acceleration, constant speed, deceleration etc.). Throughout the test, a constant flow (diluted 1:20) to a $90 \mathrm{~L}$ Tedlar bag was employed to successively determine 
the concentrations of carbon monoxide (CO), hydrocarbons (HC) and nitrogen oxides (NOx), which were then correlated to the distance travelled. A test procedure layout can be observed in Figure 1.

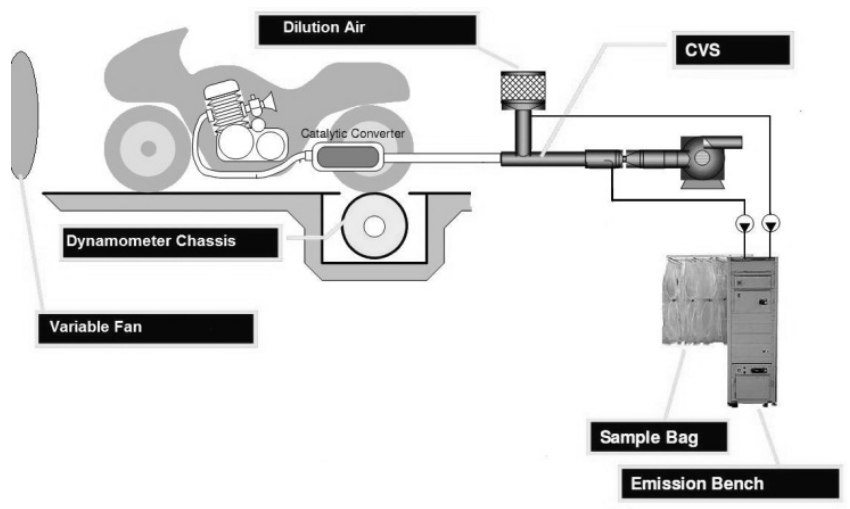

Figure 1: Test procedure layout.

For Volatile Organic Compound (VOC) sampling and speciation, $6 \mathrm{~L}$ electropolished stainless steel canisters (SUMMA) were used.

\subsection{Analysis of criteria pollutants and VOC speciation}

The analytical methodology used for the VOC speciation followed the TO-15 USEPA methodology [4] with two gas chromatographs: one to analyse the hydrocarbons from $\mathrm{C} 2$ to $\mathrm{C} 5$ and one to analyse them from $\mathrm{C} 6$ to $\mathrm{C} 12$.

The VOC analyses were performed by passing a known volume through a cryogenic pre-concentrator trap $\left(-180^{\circ} \mathrm{C}\right)$ and then injection in a $\mathrm{DB}-160 \mathrm{~m}$ column, $0.32 \mathrm{~mm}$ i.d. with $1.0 \mu \mathrm{m}$ film. The temperature was set between $-50^{\circ} \mathrm{C}$ and $180^{\circ} \mathrm{C}$, with heating at a rate of $6^{\circ} \mathrm{C} \mathrm{min}^{-1}$. The sample was divided into two different detectors: mass spectrometer, where the identification of compounds was made, and a flame ionization detector (FID), where the quantification was performed, using a calibration curve with the NPL 30 EU Directive Ozone Precursor Mixture component at $20 \mathrm{ppb}$.

Carbonyls samples were collected and analysed following the US EPA TO11A methodology [5], based on the reaction of atmospheric carbonyls with 2,4dinitrophenylhydrazine, to form the respective hydrazones. The samples were collected using two silica-C18 cartridges in series impregnated with an acid solution of 2,4-dinitrophenilhydrazine (DNPH), using an air pump (KNF UNMP $850 \mathrm{KNDC}$ ) operated at $1.0 \mathrm{~mL} \mathrm{~min}{ }^{-1}$ for 60 minutes. An ozone trap filled with potassium iodide was used before the DNPH cartridge to avoid ozone interference. After the sampling, the cartridges were sealed, wrapped with aluminium foil, stored at $4^{\circ} \mathrm{C}$ and analysed after 3 days. The detailed procedure is thoroughly explained in our previous work [6-8]. 
The extraction of carbonyl samples was performed using $5 \mathrm{~mL}$ of acetonitrile and chemical analyses were completed with high-performance liquid chromatography (HPLC), using a Perkin Elmer Series 200 equipment with UV detection at $365 \mathrm{~nm}$. The mobile phase used was $55 \%$ acetonitrile in water at $30^{\circ} \mathrm{C}$, with a $30 \mu \mathrm{L}$ volume and two $\mathrm{C} 18$ columns in series $(250 \mathrm{~mm}, 4.6 \mathrm{~mm}$ and $5.0 \mu \mathrm{m}$ ). Calibration was conducted using a standard mixture (Supelco CARB Carbonyl Mix 1) containing formaldehyde, acetaldehyde, acrolein, acetone, propionaldehyde, butyraldehyde and benzaldehyde at concentrations between 0.5 to $10.0 \mathrm{mg} \mathrm{L}^{-1}$, yielding correlation coefficients higher than 0.99 .

\subsection{Model development}

The modelling procedure was performed using the trajectory model OZIPR (Ozone Isoplot Plotting Package), which is widely accepted and well documented in the literature $[9,10]$. Other publications by our group detail its applicability $[11,12]$. In summary, the input data for a simulation are the following:

- Speciation of VOC of the local atmosphere in ppmC fractions.

- Hourly emissions of total VOC, NOx and CO in $\mathrm{kg} \mathrm{km}^{-2} \mathrm{~h}^{-1}$;

- The initial concentrations of total VOC, NOx and CO in ppm;

- Coefficients of wet and dry deposition for the main pollutants.

- Hourly weather data for temperature, pressure, humidity and mixing height;

- The actinic solar flux, used to calculate the intensity of sunlight;

- A chemical model with chemical reactions and their rate constants.

The output data are the hourly average concentrations of the main chemical species (e.g., $\mathrm{NOx}, \mathrm{CO}, \mathrm{CH}_{4}, \mathrm{O}_{3}$, and $\mathrm{PAN}$ ) and secondary pollutants isopleths for several values of VOC and NOx.

The chemical model used was the 1999 version of the SAPRC model (Statewide Air Pollution Research Centre) developed by Carter; several updates were added in later years [3,13-18].

Ambient air criteria pollutants data $\left(\mathrm{CO}, \mathrm{NOx}, \mathrm{NMHC}, \mathrm{O}_{3}\right)$ were collected by an automated monitoring station during the winter of 2011, located at the south part of the city of Rio de Janeiro, Brazil (22 $58^{\prime} 44^{\prime \prime}$ S $\left.43^{\circ} 13^{\prime} 58^{\prime \prime} \mathrm{W}\right)$, which also measured meteorological parameters (temperature, pressure and humidity). The location is adjacent to a large parking lot and is one of the busiest traffic routes in the city. It is also located next to the largest urban forest in the world, the Tijuca Forest.

The samples for VOC were collected near the automated monitoring station during the winter (August and September 2011). Samples were collected in the first morning hours when the sunlight is at a minimum and the presence of secondary pollutants can be neglected.

Canister samples were collected every five minutes and two samples were collected for three days. Samples were collected from 6:45 AM to 7:15 AM on August 29, 6:40 AM to 7:05 AM on August 30 and 7:15 AM to 7:30 AM on September 6 . 


\section{Results and discussion}

According to the INEA report [19] 321,000 tons of CO, 90,500 tons of NOx and 79,300 tons of $\mathrm{HC}$ are emitted each year in the MRRJ, which has an urban area of $2,400 \mathrm{~km}^{2}$. To obtain the hourly emissions calculations, a year was considered to have 313 days, discounting Sundays and holidays, due to low circulation of vehicles on these days. For each day, 18 hours of effective movement of vehicles were considered. Hourly emissions estimates were $6.69 \mathrm{~kg} \mathrm{NOx} \mathrm{h}^{-1} \mathrm{~km}^{-2}, 23.7 \mathrm{~kg}$ $\mathrm{CO} \mathrm{h}^{-1} \mathrm{~km}^{-2}$ and $5.87 \mathrm{~kg} \mathrm{VOC} \mathrm{h}^{-1} \mathrm{~km}^{-2}$. These values were loaded into the model to reproduce experimental hourly concentrations of $\mathrm{CO}, \mathrm{NOx}$ and $\mathrm{O}_{3}$ provided by automatic monitors for August 29, 2011. The results for the VOC speciation are detailed in Table 1.

Table 1: $\quad$ VOC speciation for August 29, 2011.

\begin{tabular}{|c|c|c|c|}
\hline VOC & Sample 1 & $\begin{array}{c}\boldsymbol{\mu g} \mathbf{~ m}^{-3} \\
\text { Sample } 2\end{array}$ & Average \\
\hline Formaldehyde * & 10.34 & 13.2 & 11.77 \\
\hline Isobutane & 0.04 & 0.08 & 0.06 \\
\hline Acetaldehyde * & 3.18 & 4.66 & 3.92 \\
\hline Acetone * & 3.80 & 4.02 & 3.91 \\
\hline Propanal * & 1.12 & 1.27 & 1.19 \\
\hline 1-butene & 2.01 & 3.09 & 2.55 \\
\hline 1,3-butadiene & 1.75 & 2.15 & 1.95 \\
\hline Butane & 17.73 & 17.4 & 17.57 \\
\hline trans-2-butene & 4.52 & 5.55 & 5.03 \\
\hline cis-2-butene & 5.59 & 7.00 & 6.29 \\
\hline 3-methyl-1-butene & 1.96 & 2.32 & 2.14 \\
\hline Isopentane & 21.05 & 20.6 & 20.83 \\
\hline Pentene & 8.41 & 10.4 & 9.41 \\
\hline 2-methyl-2-butene & 16.34 & 17.1 & 16.72 \\
\hline Pentane & 15.14 & 17.4 & 16.27 \\
\hline Isoprene & 0.80 & 1.21 & 1.01 \\
\hline trans-2-pentene & 19.39 & 23.5 & 21.45 \\
\hline cis-2-pentene & 9.88 & 11.7 & 10.79 \\
\hline 1,1-dimethyl cyclopropane & 28.35 & 27.5 & 27.92 \\
\hline 2,2-dimethyl butane & 2.43 & 2.9 & 2.66 \\
\hline Cyclopentene & 3.32 & 4.41 & 3.87 \\
\hline Cyclopentane & 9.11 & 10.1 & 9.61 \\
\hline 2,3-dimethyl butane & 6.25 & 6.22 & 6.24 \\
\hline 2-methyl pentane & 27.80 & 26.4 & 27.10 \\
\hline Butanal * & 2.36 & 2.09 & 2.23 \\
\hline 3-methyl pentane & 17.73 & 20.1 & 18.92 \\
\hline 2-methyl-1-pentene & 0.90 & 2.37 & 1.64 \\
\hline Hexene & 0.14 & 0.33 & 0.23 \\
\hline Hexane & 20.41 & 20.7 & 20.55 \\
\hline 3-hexene & 1.60 & 1.56 & 1.58 \\
\hline 3-methyl-2-pentene & 0.67 & 0.56 & 0.62 \\
\hline Methyl cyclopentane & 10.43 & 10.4 & 10.42 \\
\hline 4-methyl-2-pentene & 1.68 & 1.44 & 1.56 \\
\hline Benzene & 16.71 & 15.8 & 16.26 \\
\hline Cyclohexane & 1.75 & 1.35 & 1.55 \\
\hline 2-methyl hexane & 1.43 & 1.17 & 1.30 \\
\hline 2,3-dimethyl pentane & 0.47 & 0.45 & 0.46 \\
\hline 3-methyl hexane & 1.80 & 2.07 & 1.94 \\
\hline cis-1,3-dimethyl pentane & 0.31 & 0.33 & 0.32 \\
\hline
\end{tabular}


Table 1: $\quad$ (Continued).

\begin{tabular}{lccc}
\hline \multicolumn{1}{c}{ VOC } & Sample 1 & $\begin{array}{c}\boldsymbol{\mu} \mathbf{~ m}^{\mathbf{- 3}} \\
\text { Sample } 2\end{array}$ & Average \\
\hline Heptane & 1.39 & 1.20 & 1.29 \\
methyl cyclohexane & 0.76 & 0.67 & 0.71 \\
Toluene & 24.10 & 24.60 & 24.35 \\
2-methyl-heptane & 0.26 & 0.33 & 0.29 \\
3-methyl-heptane & 0.28 & 0.23 & 0.25 \\
ethyl benzene & 5.76 & 5.50 & 5.63 \\
Benzaldehyde * & 2.67 & 2.55 & 2.61 \\
p-xylene & 11.17 & 10.70 & 10.94 \\
m-xylene & 13.57 & 12.40 & 12.99 \\
Styrene & 4.32 & 4.05 & 4.19 \\
o-xylene & 10.71 & 10.40 & 10.56 \\
Nonane & 0.62 & 0.78 & 0.70 \\
isopropyl benzene & 1.72 & 1.57 & 1.64 \\
propyl benzene & 1.07 & 1.08 & 1.08 \\
1-ehyl-4-methyl benzene & 2.04 & 2.00 & 2.02 \\
1-ethyl-3-methyl benzene & 1.45 & 1.44 & 1.44 \\
1,3,5 trimethyl benzene & 1.55 & 1.87 & 1.71 \\
1-ethyl-2-methyl benzene & 1.14 & 1.03 & 1.08 \\
1,2,4 trimethyl benzene & 2.67 & 2.76 & 2.71 \\
Decane & 0.76 & 0.94 & 0.85 \\
1,2,3-trimethyl benzene & 1.27 & 1.12 & 1.19 \\
Indane & 0.90 & 0.78 & 0.84 \\
1-methyl-3-propyl benzene & 1.00 & 1.04 & 1.02 \\
4-ethyl 1,2 dimethyl benzene & 1.16 & 1.48 & 1.32 \\
Naphthalene & 0.90 & 1.05 & 0.97 \\
Undecane & 0.27 & 0.33 & 0.30 \\
& $\mathbf{3 9 2}$ & $\mathbf{4 1 3}$ & \\
\hline VOC sampled using TO-11A & Total & Sil & \\
\hline
\end{tabular}

*VOC sampled using TO-11A methodology. All other sampled using TO-15 methodology.

The first compound to be adjusted is $\mathrm{CO}$, as it is a primary pollutant with low reactivity. After performing the best possible fit, changing only the hourly $\mathrm{CO}$ emissions, a second adjustment was performed on the mixing layer height hourly values. It is important to remember that this adjustment is conducted around the average values obtained by the INEA emission inventory [19]. Because the mixed layer height directly influences the pollutants' concentrations, these values were adjusted to obtain the best possible fit between the simulated and measured $\mathrm{CO}$ concentration values. This value was taken as a basis for the mixing layer height and is the only measure recorded at 10:00 AM in Rio de Janeiro city.

After the simulated $\mathrm{CO}$ profile was adjusted against the experimental values, the next step was the adjustment of the NOx profile. This step was performed as an adjustment on hourly NOx emissions to reproduce the experimental values, similarly to that performed for $\mathrm{CO}$, without changing the profile of the mixed layer set above. To achieve a better adjustment of $\mathrm{CO}$ and NOx profiles, a final adjustment in their deposition rates was also made between the acceptable limits (1.0 to $1.5 \mathrm{~cm} \mathrm{~s}^{-1}$ for $\mathrm{CO}, 0.10$ to $0.20 \mathrm{~cm} \mathrm{~s}^{-1}$ for $\mathrm{NO}$ and 0.30 to $0.80 \mathrm{~cm} \mathrm{~s}^{-1}$ to $\mathrm{NO}_{2}$ ) [20].

After adjusting the $\mathrm{CO}$ and NOx profiles, the next step was to adjust the simulated and experimental results for $\mathrm{O}_{3}$. As ozone is not emitted by any significant source, but rather formed by the reactions of VOC with NOx and 
sunlight, the adjustment was made by considering the VOC hourly emissions, while emissions of NOx were adjusted. As the model does not provide data on hourly concentrations of VOC, the adjustment in VOC emissions is achieved by adjusting the $\mathrm{O}_{3}$ profile.

The $\mathrm{O}_{3}$ adjustment presented the greatest difficulties to fit simulated and experimental values. To be able to increase the $\mathrm{O}_{3}$ level in the early hours, it was necessary to significantly increase the VOC and NOx emissions. However, changing these values contributed to a mismatch in the profile of NOx and an exaggerated increase in the $\mathrm{O}_{3}$ peak. Moreover, it was not possible to adjust the $\mathrm{O}_{3}$ profile after 1:00 PM. However, the $\mathrm{O}_{3}$ profile was modelled in other studies that also used OZIPR coupled with SAPRC $[6,11]$ and showed a similar profile to others modelled in this study. Therefore, the lag of the $\mathrm{O}_{3}$ maximum value was not considered relevant because the maximum $\mathrm{O}_{3}$ model concentrations and experimental concentrations showed strong agreement. Results for $\mathrm{O}_{3}$ are presented in Figure 2.

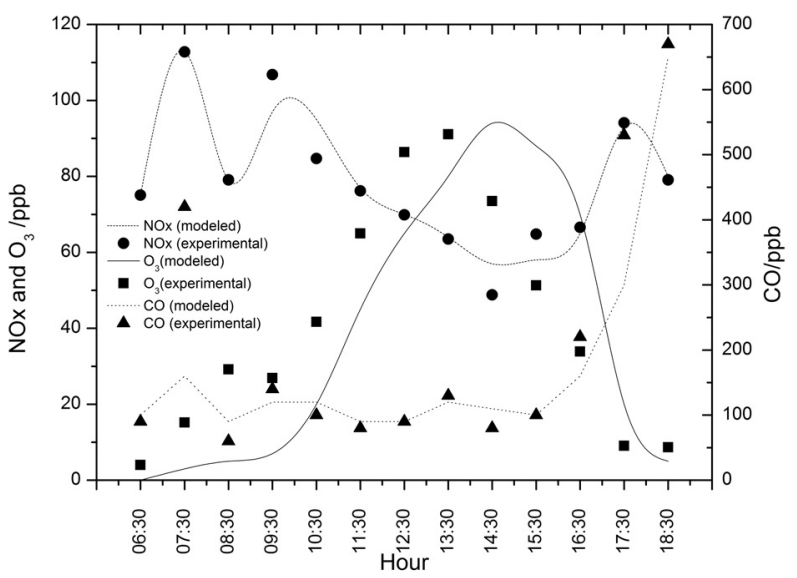

Figure 2: $\quad$ Results for experimental and modeled values of $\mathrm{O}_{3}, \mathrm{CO}$ and $\mathrm{NOx}$ for August, 29.

\subsection{Vehicular emission}

Due to difficulty in finding detailed information on the fleet of motorcycles in Brazil, a comparative study between the motorcycles emissions rate used in this work and the light vehicular fleet in use today was conducted.

To approach the real contributions of these vehicles regarding air quality, the survey was conducted in four stages. Initially, the light vehicles licensing inventory by company and model was consulted [21]. According to this inventory, approximately $77 \%$ of the fleet consists of vehicles manufactured by four companies.

The second step was to observe the amount of sales per model [22], which indicates that the best-selling car models in the country were seven models. 
In the third step, the emission rates for the best-selling models and the average values were verified and consolidated.

Automobiles and motorcycles constitute approximately $88 \%$ of the fleet in Rio de Janeiro city. Thus, the estimated emissions rates of these two types of vehicles can be considered representative for the whole of the current fleet [21].

\subsection{Scenario study}

For the creation of the scenarios, it is necessary to estimate the expected emissions increase from motorcycles. Unfortunately, there is no database available for $\mathrm{CO}, \mathrm{NOx}$ and $\mathrm{HC}$ emissions for motorcycles as there is for light vehicles. Thus, the average emissions values of two standard motorcycles were used, as described in the Methodology section for the dynamometer tests.

A comparison between average motorcycles and light vehicles emissions data is presented in Figure 3. It is important to remember that it is a conservative study, as the two evaluated motorcycles are new and attend the actual legislation.

Despite the difference in the methodologies used to measure the emissions (EC/97/24 for motorcycles and NBR 6601 for light vehicles), the average emissions found for the two motorcycles indicate higher concentrations for ethene, propene, ethyne, pentane, benzene and toluene. All of these pollutants presented average emission rates above $4 \mathrm{mg} \mathrm{km}^{-1}$.

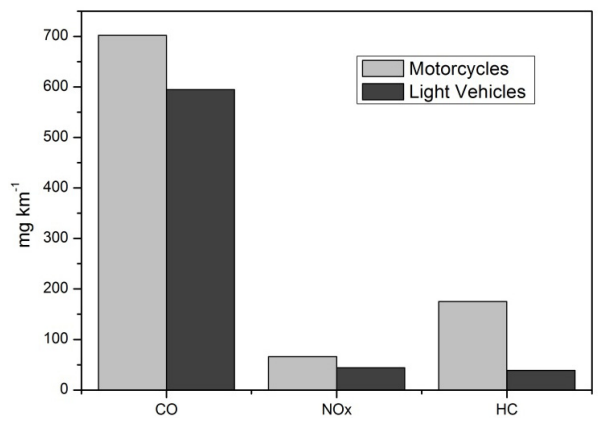

Figure 3: $\quad$ Comparison of emissions of motorcycles and light vehicles.

Regarding the fleet increase, which presents a quantitative history of motorcycles in use in Rio de Janeiro, a chart with a trend line fleet growth was prepared (Figure 4). From this graph, it was possible to obtain the estimated numbers of motorcycles for the next 3,5 and 10 years starting from October 2011.

According to Figure 4, the motorcycle fleet will number approximately 300,000 , representing an increase of $34 \%$ over the year 2011 . Two years later, the increase will be almost $61 \%$, to 360,000 motorcycles. Finally, in 10 years, the fleet growth will be approximately $132 \%$, with approximately 520,000 motorcycles in circulation.

Based on these data, three scenarios with simulations to estimate the impact for the next 3, 5 and 10 years were created. 


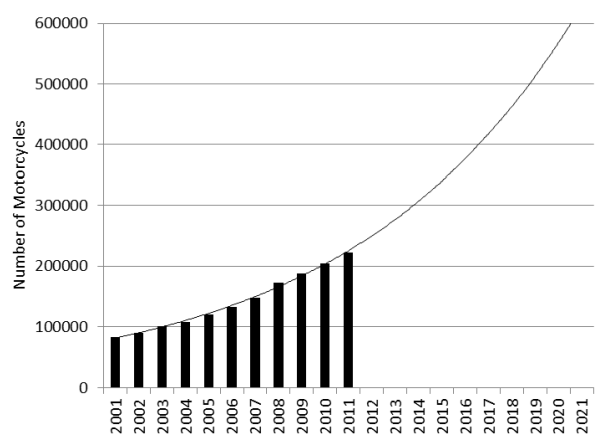

Figure 4: Trendline for the motorcycle fleet increases for the next 3, 5, and 10 years in Rio de Janeiro city.

To conduct scenarios studies, some assumptions are required. The atmosphere of a city is a combination of numerous parameters, such as emissions, topography, meteorology, and others. To choose a hypothetical scenario for a future condition of a city, it is not possible to assume changes in all parameters simultaneously because the errors associated may increase or even vanish. Thus, the study of scenarios here will take into account the following assumptions:

- Data for August 29 were used to fit the model (profiles of temperature, humidity, mixing layer and deposition rates);

- The VOC speciation of August 29 was used;

- The fleet increase of light or heavy vehicles was not considered;

- A possible variation in the composition of fuels used was not considered;

- Future reductions in emissions from vehicles and motorcycles that will surely be implemented in the future were not considered.

Thus, increases in $\mathrm{CO}, \mathrm{HC}$ and $\mathrm{NOx}$, arising from an increased motorcycle fleet, will be computed on the basis of their percentage in the fleet, leaving the hourly emissions used in the adjustment of the model weighted by increased emissions and the percentage of the fleet in MRRJ.

Assuming an increased motorcycles fleet, there will be a larger percentage of each scenario, as the vehicles have stabilized in number. The current percentage of the motorcycles in the MRRJ is $11.68 \%$. Thus, the estimated percentage of motorcycles in three years is $15.65 \%$, in 5 years is $18.81 \%$ and in 10 years is $27.10 \%$.

It is also necessary to take into consideration that an increase in the motorcycle fleet will not lead to a linear increase in $\mathrm{CO}, \mathrm{NOx}$ and $\mathrm{HC}$, as motorcycles have higher emission rates for all pollutants, for instance, $13.44 \%$ higher than the vehicles for $\mathrm{CO}, 36.36 \%$ for NOx and $336 \%$ for $\mathrm{HC}$.

The results for the ozone concentration profile in the troposphere for the scenarios studied are shown in Figure 5. It is possible to see that increasing the motorcycle fleet implies a significant increase in the ozone concentration in the troposphere. This increase is due to the high hydrocarbons emissions rate inherent in the operation of motorcycles compared to that of light vehicles. 
Currently, the ozone concentration in the troposphere of Rio de Janeiro city is relatively low, as it is routinely below $100 \mathrm{ppb}$. This fact stems from the high concentration of NOx found.

According to the model results for the scenarios chosen, the highest ozone values were recorded around 2:30 PM, reaching $120 \mathrm{ppb}$ for scenario $1,130 \mathrm{ppb}$ for scenario 2 and $160 \mathrm{ppb}$ for scenario 3 . Regarding air quality standards in accordance with those seen in Figure 5, one can predict that the reference values, national and international, will be exceeded in approximately three years. One exception to this estimate is the standard used by the EPA (320 ppb), which will not be reached.

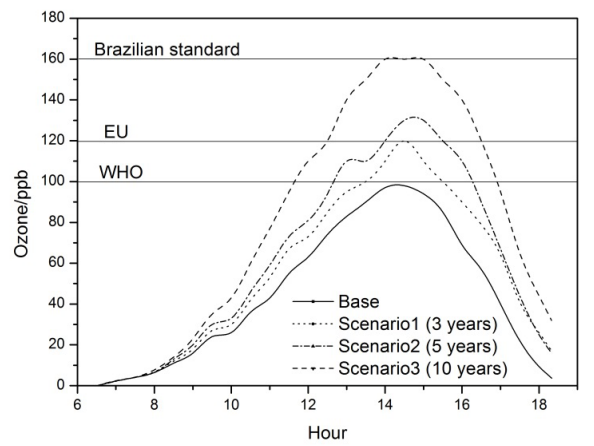

Figure 5: Ozone profile modeled for each scenario proposed.

Besides the studied scenarios results, the model was also used in multiple simulations for different maximum ozone concentrations of several VOC and NOx concentrations, providing data that generate an isopleth plot (lines of equal concentrations).

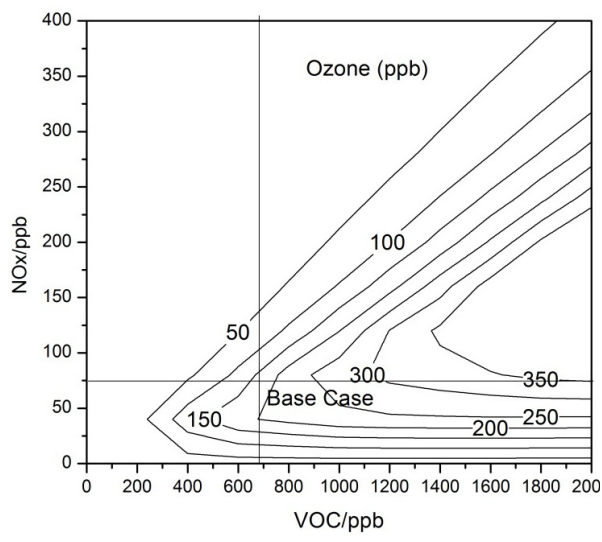

Figure 6: Ozone isopleth plot (ppb) for several concentrations of VOC and NOx for the base case on August, 29. 
In Figure 6, isopleths for maximum ozone levels of the base case can be viewed. The figure shows a scenario with little variation in the NOx rate plus a large addition of VOC, resulting in significant increases in ozone.

\section{Conclusions}

From the results obtained in this work, a significant deterioration in air quality in large cities is expected, due to increases in motorcycles fleets in urban centres and the consequent increase in emissions. In 2001, the number of motorcycles (approximately 82,000) was less than $5 \%$ of the vehicular fleet of Rio de Janeiro city. In ten years, that number is expected to exceed a rate of $9 \%$ of the total fleet (approximately 224,000) and is growing steadily.

The results of VOC speciation emitted from motorcycles indicated high emission rates for very reactive species such as ethene, propene, ethyne, pentane, benzene and toluene. All of these pollutants presented average emission rates higher than $4 \mathrm{mg} \mathrm{km}^{-1}$.

The determined results indicate that the $\mathrm{O}_{3}$ concentration in the troposphere will exceed the national standard established by the CONAMA Resolution 03/90 within three years. ${ }^{25}$ It also indicates that the emission rates of motorcycles used in this study ( $\mathrm{HC}, \mathrm{CO}$ and $\mathrm{NOx}$ ) already meet the levels recommended in all phases of PROMOT. Thus, in addition to the adoption of PROMOT, additional actions are necessary to manage the pollutants emission generated from mobile sources.

\section{Acknowledgements}

This work was partially supported by FAPERJ and CNPq.

\section{References}

[1] CETESB, 2012. www.cetesb.sp.gov.br/ar/qualidade-do-ar/31-publicacoese-relatorios.

[2] DENATRAN, 2009. www.detran.rj.gov.br/ estatisticas.veiculos/02.asp

[3] Carter, W.P.L., A detailed mechanism for the gas-phases atmospheric reactions of organic compounds. Atmospheric Environment, 24, 481-518, 1990.

[4] U.S.EPA. Compendium Method TO-15A. 1999. Determination of Volatile Organic Compounds (VOCs) in Air Collected in Specially-Prepared Canisters and Analyzed by Gas Chromatography/ Mass Spectrometry, Center for Environmental Research Information, 2 ed., Cincinnati, $\mathrm{OH}$ 45268, EPA/625/R-96/010b.

[5] U.S.EPA. Compendium Method TO-11A. 1997. Determination of Formaldehyde in Ambient Air Using Adsorbent Cartridge Followed by High Performance Liquid Chromatography (HPLC). EPA-625/R-96/010b. Cincinnati, OH: U.S. Environmental Protection Agency. 
[6] Corrêa, S.M.; Air Quality of Rio de Janeiro city: synergy between modeling and monitoring. Rio de Janeiro. Ph.D. Thesis - Chemistry Institute of Federal University of Rio de Janeiro, 2003.

[7] Corrêa, S.M.; Arbilla, G.; Martins, E.M.; Quiterio, S.L.; Guimaraes, C.S.; Gatti, L.V., Five-years of Formaldehyde and Acetaldehyde Monitoring in the Rio de Janeiro Downtown Area - Brazil. Atmospheric Environment, 44, pp. 2302-2308, 2010.

[8] Corrêa, S.M., Arbilla, G., Formaldehyde and acetaldehyde in a high traffic street of Rio de Janeiro, Brazil. Atmospheric Environment, 37, pp. 23-29, 2003.

[9] Gery, M.W.; Crouse, R.R.; User's Guide for Executing OZIPR, U.S. Environmental Protection Agency, Research Triangle Park, N. C., EPA9D2196NASA, 1990.

[10] Tonnesen, G.S. "User's Guide for Executing OZIPR Version 2.0.”; Carolina do Norte; U.S.EPA, 2000.

[11] Orlando, J.P., Gatti, L.V., Alvim, D.S., Yamazaki, A., Corrêa, S.M., Ozone precursors for the São Paulo Metropolitan Area. Science of the Total Environment, 408, pp. 1612-1620, 2010.

[12] Corrêa, S.M., Souza, C.V., Sodré, E.D., Teixeira, J.R., Volatile Organic Compound Emissions from a Landfill, Plume Dispersion and the Tropospheric Ozone Modeling. Journal of the Brazilian Chemical Society, 23(3), pp. 496-504, 2012.

[13] Carter, W.P.L., Computer Modeling of Environmental Chamber Studies of Maximum Incremental Reactivities of Volatile Organic Compounds. Atmospheric Environment, 29, pp. 2513-2527, 1995.

[14] Carter, W.P.L., Condensed Atmospheric Photooxidation Mechanisms for Isoprene. Atmospheric Environment, 22, 1996.

[15] Carter, W.P.L., Final Report to California Air Resources Board Contract 92-329 and Contract 95-308, 2000.

[16] Carter, W.P.L., Luo, D., Malkina, I.L., Final Report to the California Air Resources Board, Contract 92-345, 1997.

[17] Carter, W.P.L., Lurmann, F.W., Evaluation of a detailed gas-phase atmospheric reaction mechanism using environmental chamber data. Atmospheric Environment, 25, pp. 2771-2806, 1991.

[18] Carter, W.P.L., Atkinson, R., Development and Evaluation of a Detailed Mechanism for the Atmospheric Reactions of Isoprene and NOx. International Journal of Chemical Kinetics, 28(7), pp. 497-530, 1996.

[19] INEA. Rio de Janeiro State Environmental Institute. Annual Report, 2009.

[20] Finlayson-Pitts, B.J., Pitts Jr., J.N., Chemistry of the upper and lower atmosphere: theory, experiments, and applications; Academic Press, 1999.

[21] ANFAVEA, 2012. www.anfavea.com.br/tabelas.html

[22] FENABRAVE, 2012. www.fenabrave.org.br 